\title{
Ag Nanoparticles Drop-Casting Modification of Screen-Printed Electrodes for the Simultaneous Voltammetric Determination of $\mathrm{Cu}(\mathrm{II})$ and $\mathrm{Pb}(\mathrm{II})$
}

\author{
Clara Pérez-Ràfols ${ }^{1}$, Julio Bastos-Arrieta ${ }^{2,3}$, Núria Serrano ${ }^{1}$, José Manuel Díaz-Cruz ${ }^{1, *}$, \\ Cristina Ariño ${ }^{1}$, Joan de Pablo ${ }^{2,3,4}$ and Miquel Esteban ${ }^{1}$ \\ 1 Departament d'Enginyeria Química i Química Analítica, Facultat de Química, Universitat de Barcelona, \\ Martí i Franquès 1-11, 08028 Barcelona, Spain; claraperezrafols@ub.edu (C.P.-R.); \\ nuria.serrano@ub.edu (N.S.); cristina.arino@ub.edu (C.A.); miquelestebanc@ub.edu (M.E.) \\ 2 Departament d'Enginyeria Química, Universitat Politècnica de Catalunya (UPC), Campus Diagonal Besòs, \\ Edificio I (EEBE), Carrer Eduard Maristany 10-14, 08019 Barcelona, Spain; julio.bastos@upc.edu (J.B.-A.); \\ joan.de.pablo@upc.edu (J.d.P.) \\ 3 Barcelona Research Center for Multiscale Science and Engineering, 08019 Barcelona, Spain \\ 4 Fundació CTM Centre Tecnològic, Plaça de la Ciència 2, 08240 Manresa, Spain \\ * Correspondence: josemanuel.diaz@ub.edu; Tel.: +34-93-402-1796
}

Received: 5 May 2017; Accepted: 17 June 2017; Published: 21 June 2017

\begin{abstract}
A new silver nanoparticle modified screen-printed electrode was developed and applied to the simultaneous determination of $\mathrm{Pb}(\mathrm{II})$ and $\mathrm{Cu}(\mathrm{II})$. Two different types of silver nanoparticles with different shapes and sizes, Ag nanoseeds and Ag nanoprisms, were microscopically characterized and three different carbon substrates, graphite, graphene and carbon nanofibers, were tested. The best analytical performance was achieved for the combination of Ag nanoseeds with a carbon nanofiber modified screen-printed electrode. The resulting sensor allowed the simultaneous determination of $\mathrm{Pb}(\mathrm{II})$ and $\mathrm{Cu}(\mathrm{II})$ at trace levels and its applicability to natural samples was successfully tested with a groundwater certified reference material, presenting high reproducibility and trueness.
\end{abstract}

Keywords: silver nanoparticles; screen-printed electrodes; anodic stripping voltammetry; metal ions; nanoparticle drop-casting

\section{Introduction}

Voltammetric stripping techniques have been widely applied to trace metal ions determination because they present excellent detection limits, great sensitivity to the presence of different metals and capacity to multimetal determination with a relatively low cost [1]. For several decades, these techniques mainly used the hanging mercury drop electrode (HMDE) as a working electrode. HMDE presents several advantages such as new drops being formed continuously, which avoids problems related to contamination, its great reproducibility or its extensive cathodic potential range (from $+0.4 \mathrm{~V}$ to $-2.5 \mathrm{~V}$ according to supporting electrolyte) among others [2]. However, potential toxicity risks associated to mercury use and disposal, together with the difficulty to adapt HMDE to sensor devices and flow systems, have led to the introduction of new working electrode materials throughout the years.

Bismuth film electrodes (BiFE) were proposed in 2000 as an alternative to HMDE since they offered properties close to those of mercury with the advantages of being more environmentally friendly and easily adaptable to sensor devices and flow systems [3]. BiFE, though, presents a narrower anodic potential range since the stripping peak of bismuth appears at $-0.3 \mathrm{~V}$. This fact prevents the use of BiFE prepared via ex situ plating or preplated method to the determination of more easily oxidizable metals like $\mathrm{Cu}(\mathrm{II})$, whereas the in situ BiFE approach, where Bi(III) ions are electrochemically deposited 
on the electrode surface during the analysis, cannot be used to the determination of copper either because $\mathrm{Bi}(\mathrm{III})$ and $\mathrm{Cu}(\mathrm{II})$ ions compete for the surface sites [4,5].

The anodic potential range was slightly extended with the introduction of antimony film electrodes (SbFE) in 2007 since the stripping peak of antimony does not appear until $-0.1 \mathrm{~V}$ [6]. This potential range, though, is still not wide enough to allow the determination of copper with an ex situ SbFE approach. Better results were obtained with an SbFE prepared via in situ, where $\mathrm{Cu}$ (II) was successfully determined [7]. However, the use of in situ SbFEs implies the addition of Sb(III) ions to the sample solution, causing a slight overlapping between both the $\mathrm{Cu}(\mathrm{II})$ and the $\mathrm{Sb}$ (III) peaks, which is not an ideal situation.

Other types of working electrodes like solid electrodes or chemically modified electrodes (CME) have been successfully applied to the determination of $\mathrm{Cu}$ (II). These types of electrodes usually present a much wider anodic potential range than bismuth and antimony based electrodes. Nevertheless, CMEs usually present longer manufacturing times, whereas, when working with solid electrodes, it is difficult to control their surface in a reproducible manner and the peaks appear distorted and with excessive noise [8]. It should be pointed out that the use of under potential deposition (UPD) combined with stripping techniques for analytical applications can overcome some of the major disadvantages related to solid electrodes [9].

Another field that brings more possibilities to the development of improved electrochemical sensors is the use of nanomaterials. At this small scale, materials present some unique optical, mechanical, electrical and chemical properties and, compared to electrodes based on bulk materials, nanomaterials present some enhanced properties such as increased electrode surface area, increased mass-transport rate and faster electron transfer [10]. In this sense, nanostructured modified electrodes ranging from carbon-based nanomaterials to metallic nanoparticles have been studied for metal ion determination [10-12]. Concerning metallic nanoparticles, good results have been obtained using bismuth, antimony and gold among others [10,11]. Silver nanoparticles, on the other hand, are also being explored due to their good chemical and physical properties as well as their inexpensiveness. Some good results have already been reported for the determination of $\mathrm{Sb}$ (III) [13], $\mathrm{Cr}$ (VI) [14], $\mathrm{Pb}$ (II) and Cd(II) [15]. Furthermore, electrodes based on silver nanoparticles present a wider anodic potential range compared to SbFEs, which makes them good candidates for the determination of $\mathrm{Cu}$ (II).

Silver nanoparticles electrodes can be based on different supports. In this sense, the appearance of the screen-printing technology has represented a huge progress thanks to the disposable character, good reproducibility and low-cost commercial availability of screen-printed devices. Moreover, the possibility of using a great diversity of compositions of printing inks, as well as the easy modification of their surface and the design versatility are important advantages of these devices $[3,16]$. These exciting benefits of screen-printed electrodes as supports over traditional based electrodes for metal ion determination have also been reported by Honeychurch et al. [17].

Inspired by both, the good properties of silver nanoparticles and the great features of screen-printed technology, in this work, we report for the first time the determination of $\mathrm{Cu}$ (II) with a silver-nanoparticle based- screen-printed electrode. In this reported electrode silver nanoparticles, Ag-nanoseeds and Ag-nanoprisms were simply prepared and easily incorporated to commercially available screen-printed electrodes. These silver-nanoparticles were microscopically and analytically studied. Furthermore, the determination of $\mathrm{Pb}$ (II) and its interaction with $\mathrm{Cu}$ (II) have also been considered. Additionally, the simultaneous determination of $\mathrm{Pb}(\mathrm{II})$ and $\mathrm{Cu}(\mathrm{II})$ in a certified groundwater sample was successfully achieved.

\section{Materials and Methods}

\subsection{Chemicals}

Certified reference material, groundwater $\left(\mathrm{BCR}^{\circledR}-610\right)$, was provided by Sigma-Aldrich (St. Louis, MO, USA). All other reagents used were purchased from Panreac (Barcelona, Spain) and Merck 
(Darmstadt, Germany) analytical grade. Daily $\mathrm{Cu}(\mathrm{II})$ and $\mathrm{Pb}$ (II) standard solutions were prepared by appropriate dilution of stock solutions $10^{-2} \mathrm{~mol} \cdot \mathrm{L}^{-1}$, prepared from $\mathrm{Cu}\left(\mathrm{NO}_{3}\right)_{2} \cdot 3 \mathrm{H}_{2} \mathrm{O}$ and $\mathrm{Pb}\left(\mathrm{NO}_{3}\right)_{2} \cdot 4 \mathrm{H}_{2} \mathrm{O}$, respectively, and complexometrically standardized [18]. Acetate buffer $0.1 \mathrm{~mol} \cdot \mathrm{L}^{-1}$ ( $\mathrm{pH}$ 4.5) was used for $\mathrm{pH}$ control and ultrapure water (Milli-Q plus 185 system, Millipore, Billerica, MA, USA) was used in all experiments.

Silver nitrate, poly(sodium styrenesulphonate) (PSSS), trisodium citrate, sodium borohydride and ascorbic acid were used for the preparation of Ag-nanoseeds and Ag-nanoprims, all from Sigma-Aldrich (St. Louis, MO, USA).

\subsection{Apparatus}

For stripping voltammetric measurements, an Autolab System PGSTAT12 (EcoChemie, Utrecht, the Netherlands), in its multichannel configuration, attached to a Metrohm 663 VA Stand (Metrohm, Herisau, Switzerland) was used. GPES Multichannel 4.7 software package (EcoChemie, Utrecht, The Netherlands) was employed for data acquisition.

$\mathrm{Pt}$ wire and $\mathrm{Ag}|\mathrm{AgCl}| \mathrm{KCl}\left(3 \mathrm{~mol} \cdot \mathrm{L}^{-1}\right)$ (Metrohm, Herisau, Switzerland) were used as auxiliary and reference electrodes, respectively. The working electrode was either a carbon screen-printed electrode (SPCE), a carbon nanofiber modified screen-printed electrode (SPCNFE) or a graphene modified screen-printed electrode (SPGPHE) modified with silver nanoparticles and connected to the Autolab Systems by means of a flexible cable (ref. CAC, DropSens). SPCE, SPCNFE and SPGPHE were disk electrodes of $4 \mathrm{~mm}$ diameter purchased from Dropsens (Oviedo, Spain) (ref. 110, DS SPCE, ref. $110 \mathrm{CNF}$, DS SPCE and ref. 110GPH, DS SPCE respectively).

A pH-meter Basic 20 (Crison Instruments, Barcelona, Spain) was used for $\mathrm{pH}$ measurements.

Surface morphology characterization was performed by a scanning electron microscope JSM 7100FE from JEOL (Tokyo, Japan).

Transmission Electron Microscopy (TEM) images were obtained using a JEM Jeol 2100 microscope (Peabody, MA, USA) at 200 kV, coupled with an Energy-Dispersive Spectrometer (Inca X-Sight from Oxford Instruments, Abingdon, UK).

\subsection{Synthesis and Characterization of $A g$ Nanoseeds and $A g$ Nanoprisms}

The preparation of different types of Ag nanoparticles was carried out by Seed Mediated Approach Methodology $[19,20]$. Seed nucleation is due to $\mathrm{NaBH}_{4}$ (as strong reducing agent) that leads to the formation of small spherical nanoparticles, with trisodium citrate and PSSS as stabilizers. For nanoprism formation, ascorbic acid acts as reducing agent (softer than $\mathrm{NaBH}_{4}$ ) with preferential axial growth in crystallization. This fact leads to the formation of the shape defined nanoprisms, with sodium tricitrate used as nanoprism stabilizer. Thus, Ag nanoseeds were produced by combining aqueous trisodium citrate $\left(5 \mathrm{~mL}, 2.5 \mathrm{mmol} \cdot \mathrm{L}^{-1}\right)$, aqueous PSSS $\left(0.25 \mathrm{~mL}, 500 \mathrm{mg} \cdot \mathrm{L}^{-1}\right)$ and aqueous $\mathrm{NaBH}_{4}\left(0.3 \mathrm{~mL}, 10 \mathrm{mmol} \cdot \mathrm{L}^{-1}\right.$, freshly prepared) followed by addition of aqueous $\mathrm{AgNO}_{3}(5 \mathrm{~mL}$, $0.5 \mathrm{mmol} \cdot \mathrm{L}^{-1}$ ) at a rate of $2 \mathrm{~mL} \cdot \mathrm{min}^{-1}$ while stirring continuously. Then, a specific Ag nanoprism sample was prepared by combining $5 \mathrm{~mL}$ distilled water, aqueous ascorbic acid $\left(75 \mu \mathrm{L}, 10 \mathrm{mmol} \cdot \mathrm{L}^{-1}\right)$ and $2.5 \mathrm{~mL}$ of the previously synthesized $\mathrm{Ag}$ nanoseeds, followed by addition of aqueous $\mathrm{AgNO}_{3}$ $\left(3 \mathrm{~mL}, 0.5 \mathrm{mmol} \cdot \mathrm{L}^{-1}\right)$ at a rate of $1 \mathrm{~mL} \cdot \mathrm{min}^{-1}$. After synthesis, aqueous trisodium citrate $(0.5 \mathrm{~mL}$, $25 \mathrm{mmol} \cdot \mathrm{L}^{-1}$ ) was added to stabilize the particles. Milli-Q Water was used throughout all solutions.

The size distribution of the prepared nanoparticles was obtained by direct observation of the TEM images and the construction of the corresponding size distribution histograms. These measurements were performed using the ImageJ Software $(1.48 \mathrm{~V})$, and the histograms obtained were adjusted to a three-parameter Gaussian curve (Equation (1)), where $x_{0}$ is the mean diameter (to which most nanoparticles correspond), $b$ is the standard deviation and $a$ is a statistical parameter related to this fitting. Histograms were calculated using Excel 2010 (Microsoft, Redmond, WA, USA), and the 
equation was adjusted with SigmaPlot 11.0 (Systat Software, San José, CA, USA). For Ag nanoprisms, heights were used as reference for the diameter value:

$$
y=a e^{\left[-0.5\left(\frac{x_{0}-x}{b}\right)^{2}\right]} .
$$

\subsection{Preparation of Ag-Nanoparticles-SPCNFE}

Ag-nanoparticles-SPCNFE was prepared by drop-casting $40 \mu \mathrm{L}$ of silver nanoparticles solution onto the electrode surface and drying it for $30 \mathrm{~min}$ at $50{ }^{\circ} \mathrm{C}$.

\subsection{Voltammetric Measurements}

For voltammetric stripping determinations of $\mathrm{Pb}$ (II) and $\mathrm{Cu}$ (II) using Ag-nanoparticles-SPCNFE, both metal ions were deposited at a deposition potential $\left(\mathrm{E}_{\mathrm{d}}\right)$ of $-1.1 \mathrm{~V}$, applied with stirring, during a deposition time $\left(t_{d}\right)$ of $120 \mathrm{~s}$. Deposition was followed by a rest period $\left(t_{r}\right)$ of $5 \mathrm{~s}$ and then the potential was scanned from -1.1 to $0.15 \mathrm{~V}$ using pulse times of $50 \mathrm{~ms}$, step potentials of $5 \mathrm{mV}$ and pulse amplitudes of $50 \mathrm{mV}$.

Linear calibration plots for both separate and simultaneous determinations of $\mathrm{Cu}(\mathrm{II})$ and $\mathrm{Pb}(\mathrm{II})$ were performed by increasing metal ion concentrations in $0.1 \mathrm{~mol} \cdot \mathrm{L}^{-1}$ acetate buffer $(\mathrm{pH} 4.5)$.

The analysis of the certified groundwater sample was performed by the standard addition calibration method. First of all, a volume of the sample $\left(\mathrm{BCR}^{\circledR}-610\right)$ was adjusted to $\mathrm{pH} 4.5$ with sodium acetate and the scan was recorded. Then, four aliquots of $\mathrm{Cu}(\mathrm{II})$ and $\mathrm{Pb}$ (II) standard solutions were added and the respective curves were recorded.

\section{Results and Discussion}

\subsection{Electron Microscopy Characterization of Ag-Nanoparticles-SPCNFE}

The incorporation of nanoparticles (NPs) in sensing systems derives to the enhancement and customization of the electrochemical features (e.g., oxidation or reduction current onto a transducing platform), which offers novel option for electroanalytical purposes in environmental and biological fields [21]. Consequently, the incorporation of Ag-NPs to commercially available screen-printed electrodes implies the increase of electrocatalytically active zones on the structure of the composite material. SEM images of the surface of SPCNFE modified with Ag-nanoseeds (Figure 1A,B) and Ag-nanoprisms (Figure 1C,D) show, in comparison to the bare SPCNFE (Figure 1E), the dispersion of these NPs all over the electrode surface (white dots). This can explain the capability to improve the electrochemical performance in comparison with the non-modified SPCNFE, as previously observed in other electrochemical systems modified with nanomaterials [22].

Seed mediated approach synthesis of nanostructures is a multistep methodology [23] based on the first fast crystallization of nanoseeds, which can be used for further nucleation and customized growth of shape defined nanoprisms of larger size [24]. TEM characterization of spherical Ag-nanoseeds (Figure 2A,B) and shaped defined Ag-nanoprisms (Figure 2C,D) provides valuable morphological information of the materials incorporated to SPCNFE matrix.

\subsection{Enhanced Modification of SPE with Ag-Nanoparticles}

The attachment of the silver nanoparticles to the screen-printed electrodes surface was firstly optimized using Ag-nanoseeds as a model of silver nanoparticles. Different drop volumes and drying times were tested and the best results were obtained by depositing a single drop of $40 \mu \mathrm{L}$ of the Ag-nanoseeds solution to the electrode surface and drying it in the oven at $50{ }^{\circ} \mathrm{C}$. 

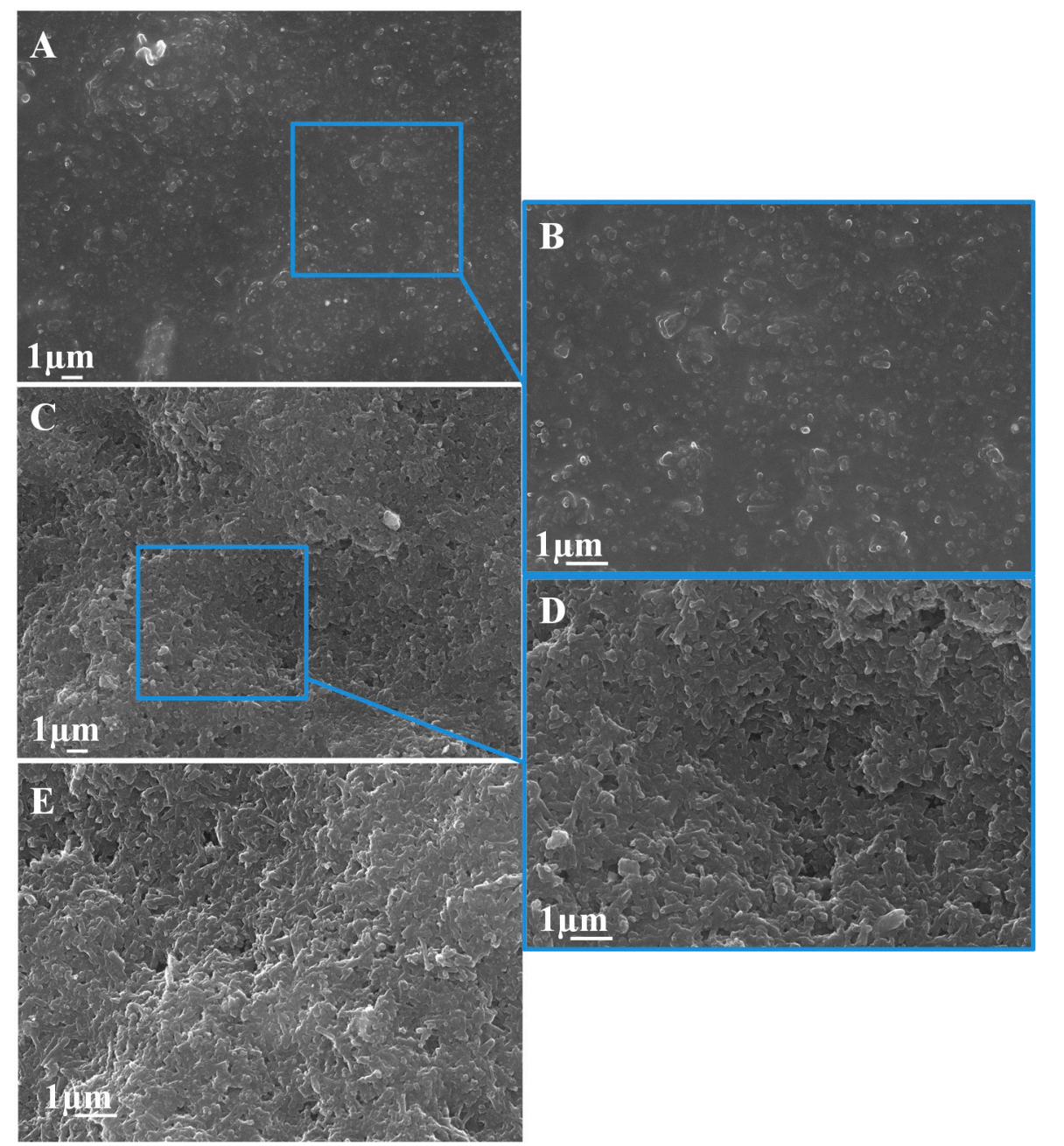

Figure 1. SEM micrographs of Ag-nanoseeds-SPCNFE (A,B), Ag-nanoprisms-SPCNFE (C,D) and bare SPCNFE (E). Magnification of $\mathrm{E}=\mathrm{A}=\mathrm{C}<<<\mathrm{B}=\mathrm{D}$.

In order to see the enhancement of the electrochemical response provided by the silver nanoparticles screen-printed electrode, firstly, the measurements of a solution containing $100 \mu \mathrm{g} \cdot \mathrm{L}^{-1}$ of $\mathrm{Cu}$ (II) and $\mathrm{Pb}$ (II) were carried out on both SPCE and Ag-nanoseeds-SPCE. As it can be seen in Figure 3, the attachment of the silver nanoparticles on the screen-printed surface considerably increases the voltammetric response for both considered metal ions, suggesting that a sensor based on the modification with Ag-nanoparticles could be a better alternative for the determination of $\mathrm{Cu}$ (II) and $\mathrm{Pb}(\mathrm{II})$.

Taking into account that it has been reported that the use of carbon based nanomaterials supports improves the analytical performance of sensors [25], three different carbon-based screen-printed substrates, graphite, graphene and carbon nanofibers, were compared prioritizing the repeatability and reproducibility of the resulting sensor. In this sense, stripping measurements of a solution containing $100 \mu \mathrm{g} \cdot \mathrm{L}^{-1}$ of $\mathrm{Cu}(\mathrm{II})$ and $\mathrm{Pb}(\mathrm{II})$ in acetate buffer $\mathrm{pH} 4.5$ were carried out. The repeatability was calculated from 10 repetitive measurements using the same Ag-nanoseeds-SPE, whereas the reproducibility was measured from three different Ag-nanoseeds-SPE units within a series of 10 repetitive measurements. Ag-nanoseeds-SPCE was the least repetitive sensor, with relative standard deviations (RSD) yielding $18.1 \%$ for $\mathrm{Cu}$ (II) and $20.1 \%$ for $\mathrm{Pb}(\mathrm{II})$. Better repeatability results were obtained for Ag-nanoseeds-SPCNFE (3.6\% for $\mathrm{Cu}$ (II) and 5.5\% for Pb(II)) and Ag-nanoseeds-SPGPHE (3.2\% for $\mathrm{Cu}(\mathrm{II})$ and $3.1 \%$ for $\mathrm{Pb}(\mathrm{II})$ ). This fact could be attributed to the enlarged surface area and 
rugosity provided by the nanostructured carbon materials, which help retaining the Ag-nanoseeds onto the electrode surface.
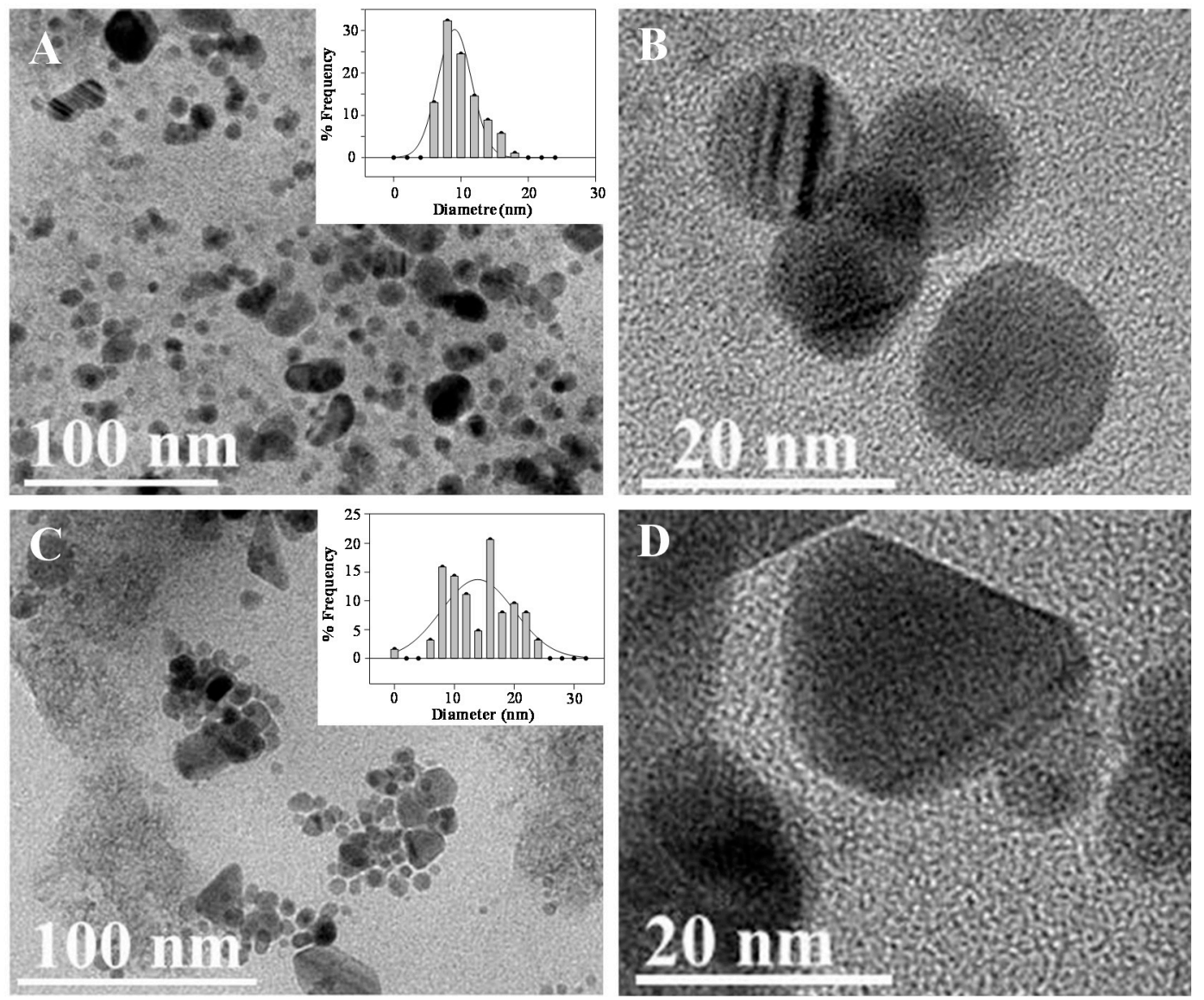

Figure 2. TEM micrographs of $9.1 \pm 0.4 \mathrm{~nm}$ spherical Ag-nanoseeds $(\mathbf{A}, \mathbf{B})$ and triangular shaped $14.0 \pm 0.9 \mathrm{~nm}$ Ag-nanoprisms $(\mathbf{C}, \mathbf{D})$ with the corresponding size distribution histograms (insets in $\mathbf{A}$ and $\mathrm{C})$. Magnification of $\mathrm{A}=\mathrm{C}<<<\mathrm{B}=\mathrm{D}$.

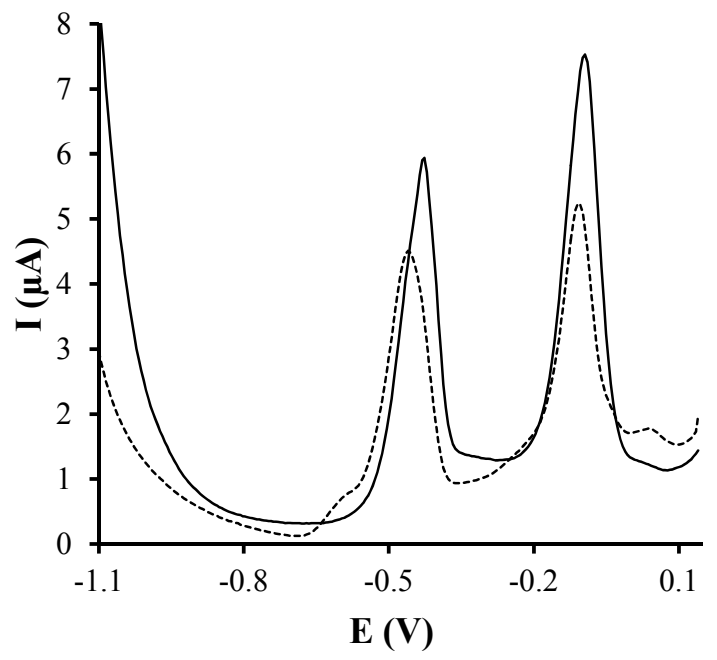

Figure 3. Stripping voltammetric measurements of a solution containing $100 \mu \mathrm{g} \cdot \mathrm{L}^{-1}$ of $\mathrm{Cu}(\mathrm{II})$ and $\mathrm{Pb}$ (II) at $\mathrm{pH} 4.5$ using an $\mathrm{E}_{\mathrm{d}}$ of $-1.1 \mathrm{~V}$ during a $\mathrm{t}_{\mathrm{d}}$ of $120 \mathrm{~s}$ on Ag-nanoseeds-SPCE (solid line) and SPCE (dashed line). 
Given the low repeatability observed for Ag-nanoseeds-SPCE, this substrate was discarded and the reproducibility was studied for both Ag-nanoseeds-SPCNFE and Ag-nanoseeds-SPGPHE. In this case, Ag-nanoseeds-SPCNFE provided better results $(5.2 \%$ for $\mathrm{Cu}$ (II) and $8.1 \%$ for $\mathrm{Pb}$ (II)) compared to Ag-nanoseeds-SPGPHE (19.3\% for $\mathrm{Cu}(\mathrm{II})$ and $15.2 \%$ for $\mathrm{Pb}(\mathrm{II})$ ). This poor reproducibility values obtained for Ag-nanoseeds-SPGPHE could be attributed to the low homogeneity between the different units commercially purchased. This fact was previously observed for the preparation of antimony film coated on SPGPHE [26].

In view of these results, SPCNFE was selected as the optimal carbon substrate and its repeatability and reproducibility were also studied for Ag-nanoprisms, yielding 3.6\% and $6.3 \%$ for $\mathrm{Cu}$ (II) and $5.1 \%$ and $9.3 \%$ for $\mathrm{Pb}(\mathrm{II})$, respectively. As it can be seen, similar repeatability and reproducibility were obtained for both Ag-nanoseeds and Ag-nanoprisms. Furthermore, these reproducibility values are also in agreement with reproducibility values reported with silver nanoparticles modified electrodes for $\mathrm{Sb}$ (III) [13], $\mathrm{Pb}$ (II), $\mathrm{Cd}(\mathrm{II})$ [15] and $\mathrm{Cr}(\mathrm{IV})$ [14].

\subsection{Electrochemical Parameters and Calibration Data}

Once the preparation of the silver nanoparticle modified electrodes was optimized, different electrochemical parameters were optimized for the simultaneous determination of $\mathrm{Pb}(\mathrm{II})$ and $\mathrm{Cu}(\mathrm{II})$. In this sense, stripping measurements of a solution containing $100 \mu \mathrm{g} \cdot \mathrm{L}^{-1}$ of $\mathrm{Cu}$ (II) and $\mathrm{Pb}$ (II) in acetate buffer $\mathrm{pH} 4.5$ were carried out at several deposition potentials $\left(\mathrm{E}_{\mathrm{d}}\right)$ ranging from -0.6 to $-1.2 \mathrm{~V}$ and using a deposition time $\left(t_{d}\right)$ of $120 \mathrm{~s}$ as a compromise between peak area and analysis time. When applying $\mathrm{E}_{\mathrm{d}}$ between $-0.6 \mathrm{~V}$ and $-0.9 \mathrm{~V}$, two overlapped peaks were observed in the copper oxidation region. The reasons for such behavior are not clear but could be related to the stabilization of $\mathrm{Cu}(\mathrm{I})$ onto the electrode surface. Anyway, using more negative $E_{d}$, a single peak clearly corresponding to the $\mathrm{Cu}(\mathrm{II})$ oxidation was observed. This peak increased when the $\mathrm{E}_{\mathrm{d}}$ was shifted from -0.95 to $-1.1 \mathrm{~V}$ and decreased at more negative potentials. Therefore, an $E_{d}$ of $-1.1 \mathrm{~V}$ was selected as the optimal for the determination of $\mathrm{Cu}(\mathrm{II})$ and $\mathrm{Pb}$ (II).

The anodic range of the Ag-nanoparticles-SPCNFE was also studied. It was observed that the stripping peak associated to $\mathrm{Ag} / \mathrm{Ag}(\mathrm{I})$ did not appear until $0.2 \mathrm{~V}$, which perfectly allows the determination of $\mathrm{Cu}(\mathrm{II})$ which appears at ca. $-0.11 \mathrm{~V}$. It should be pointed out that this anodic range is wider than that provided by a silver screen-printed electrode where the stripping peak associated to the oxidation of $\mathrm{Ag}$ appears at ca. $-0.03 \mathrm{~V}$. This fact is in agreement with the behavior showed by a rotating silver electrode [25], where $\mathrm{Cu}$ (II) cannot either be determined and could be attributed to nanomaterials having different redox potentials than bulk materials [27].

Once the electrochemical parameters were optimized, separate calibrations of $\mathrm{Cu}$ (II) and $\mathrm{Pb}$ (II) were carried out on both Ag-nanoseeds-SPCNFE and Ag-nanoprisms-SPCNFE sensors (Figure 4). Table 1 reports the sensitivities, correlations, linear ranges and limits of detections (LOD) obtained. Sensitivities were calculated as the slope of the calibration curve, whereas LODs and LOQs were calculated as three and ten times, respectively, the standard deviation of the intercept over the slope. As it can be observed, Ag-nanoprisms-SPCNFE provides lower sensitivities compared to Ag-nanoseeds-SPCNFE, which also presents slightly better LODs. This fact could be attributed to the spherical shape of Ag-nanoseeds, which provides a larger surface area, as well as to the wetting behavior of the nanoparticle containing solutions that leads to a more homogeneously distributed layer. Nevertheless, in both cases, the obtained LODs are similar or even better than those provided in the literature using CMEs [28,29], in situ SbFE [7,30,31] or silver nanoparticles based electrodes [32] for $\mathrm{Cu}$ (II) and CMEs [28,33,34], SbFEs [6], BiFEs [3] or silver nanoparticles based electrodes [15,32] for $\mathrm{Pb}(\mathrm{II})$. It should also be pointed out that, although the linear range for $\mathrm{Cu}(\mathrm{II})$ is similar for both Ag-nanoseeds-SPCNFE and Ag-nanoprisms-SPCNFE, in the case of Pb(II), the electrode surface is easily saturated when the Ag-nanoprisms-SPCNFE is used, which results in a significantly narrower linear range. 

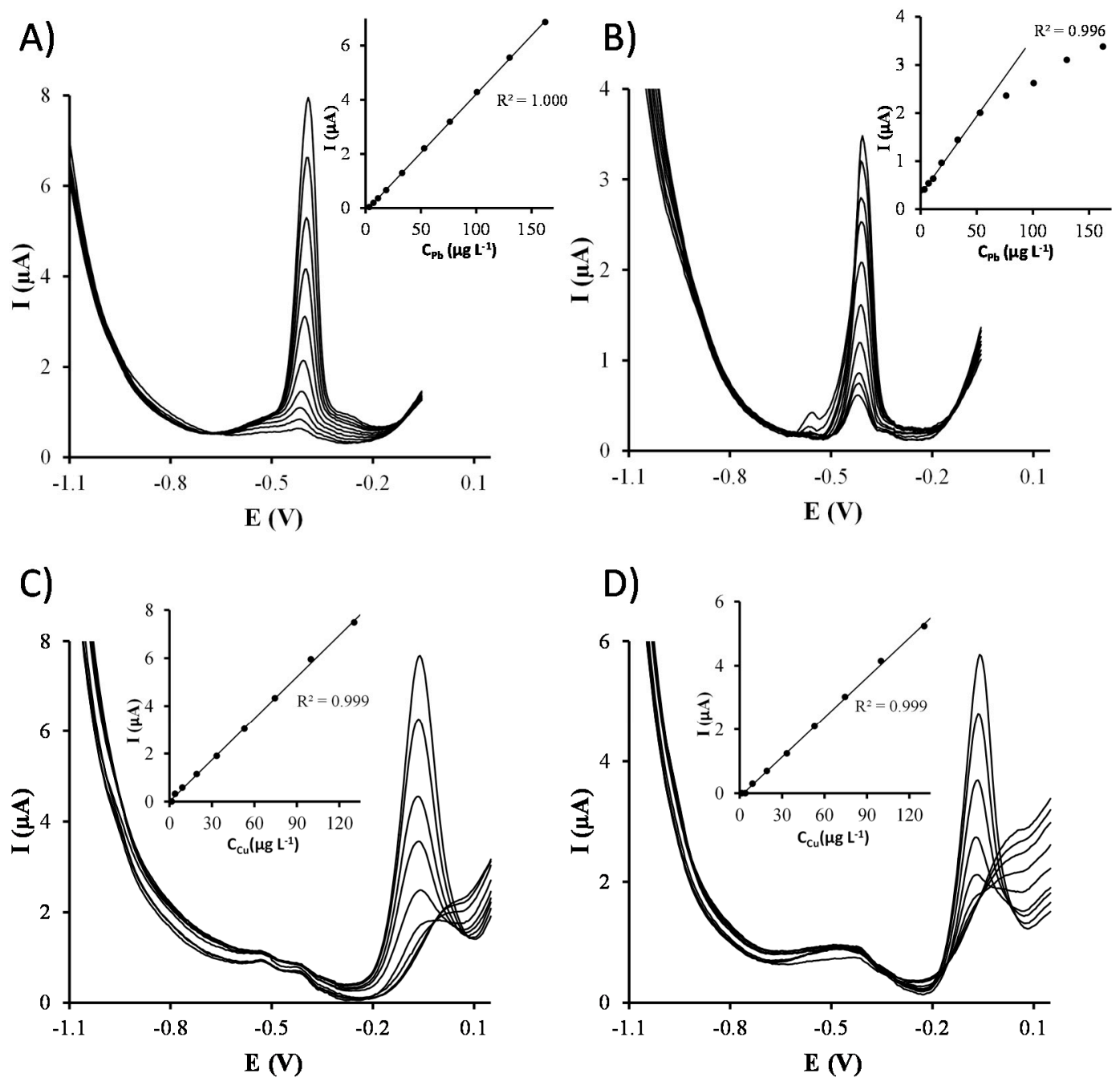

Figure 4. Stripping voltammetric measurements and calibration curves (insets) obtained for the individual calibration of $\mathrm{Pb}$ (II) $(\mathbf{A}, \mathbf{B})$ and $\mathrm{Cu}(\mathrm{II})(\mathbf{C}, \mathbf{D})$ in acetate buffer $\mathrm{pH} 4.5$ using an Ag-nanoseeds-SPCNFE $(\mathbf{A}, \mathbf{C})$ and an Ag-nanoprisms-SPCNFE (B,D) at an $E_{d}$ of $-1.1 \mathrm{~V}$ and a $t_{d}$ of $120 \mathrm{~s}$.

Table 1. Calibration data for both separate and simultaneous determination of $\mathrm{Pb}$ (II) and $\mathrm{Cu}$ (II) on Ag-nanoseeds-SPCNFE and Ag-nanoprisms-SPCNFE at $\mathrm{E}_{\mathrm{d}}$ of $-1.1 \mathrm{~V}, \mathrm{t}_{\mathrm{d}}$ of $120 \mathrm{~s}$ and $\mathrm{pH} 4.5$. The standard deviations are denoted by parenthesis.

\begin{tabular}{|c|c|c|c|c|}
\hline & \multicolumn{2}{|c|}{ Separate } & \multicolumn{2}{|c|}{ Simultaneous } \\
\hline & $\mathrm{Pb}(\mathrm{II})$ & $\mathrm{Cu}(\mathrm{II})$ & $\mathrm{Pb}(\mathrm{II})$ & $\mathrm{Cu}(\mathrm{II})$ \\
\hline \multicolumn{5}{|l|}{ Ag-nanoseeds-SPCNFE } \\
\hline Sensitivity $\left(\mathrm{nA} \cdot \mu \mathrm{g}^{-1} \cdot \mathrm{L}\right)$ & $43.3(0.2)$ & $57.5(0.7)$ & $43(1)$ & $73(2)$ \\
\hline $\mathrm{R}^{2}$ & 1.000 & 0.999 & 0.998 & 0.998 \\
\hline Linear range $^{1}\left(\mu \mathrm{g} \cdot \mathrm{L}^{-1}\right)$ & $3.2-162.5$ & $7.6-130.7$ & $6.6-53.5$ & $10.0-77.0$ \\
\hline $\operatorname{LOD}\left(\mu \mathrm{g} \cdot \mathrm{L}^{-1}\right)$ & 0.96 & 2.29 & 1.98 & 2.99 \\
\hline \multicolumn{5}{|l|}{ Ag-nanoprisms-SPCNFE } \\
\hline Sensitivity $\left(\mathrm{nA} \cdot \mu \mathrm{g}^{-1} \cdot \mathrm{L}\right)$ & $32.3(0.9)$ & $41.4(0.6)$ & $25.9(0.7)$ & $34.4(0.5)$ \\
\hline $\mathrm{R}^{2}$ & 0.996 & 0.999 & 0.997 & 0.999 \\
\hline Linear range $^{1}\left(\mu \mathrm{g} \cdot \mathrm{L}^{-1}\right)$ & $7.3-53.1$ & 9.9-130.7 & $7.8-53.5$ & $8.3-100.7$ \\
\hline $\mathrm{LOD}\left(\mu \mathrm{g} \cdot \mathrm{L}^{-1}\right)$ & 2.20 & 2.98 & 2.35 & 2.49 \\
\hline
\end{tabular}

${ }^{1}$ The lowest value of the linear range was considered from LOQ. 
In order to study the interaction between $\mathrm{Cu}$ (II) and $\mathrm{Pb}$ (II) ions, simultaneous calibrations of both target metal ions were also carried out on Ag-nanoseeds-SPCNFE and Ag-nanoprisms-SPCNFE (Figure 5 and Table 1). It can be observed that both metals interact with each other, resulting in changes of the sensitivities as compared to separate calibrations. The most notorious thing, though, is the shortening of the linearity range probably caused by the competition of $\mathrm{Cu}$ (II) and $\mathrm{Pb}$ (II) for the active sites of the electrode surface.

Although both Ag-nanoseeds-SPCNFE and Ag-nanoprisms-SPCNFE present a similar analytical performance regarding repeatability, reproducibility, linear range and LODs, the higher sensitivities achieved by Ag-nanoseeds-SPCNFE together with the fact that Ag-nanoseeds require fewer steps to be synthesized than Ag-nanoprisms, Ag-nanoseeds-SPCNFE was selected to test its applicability in natural samples.
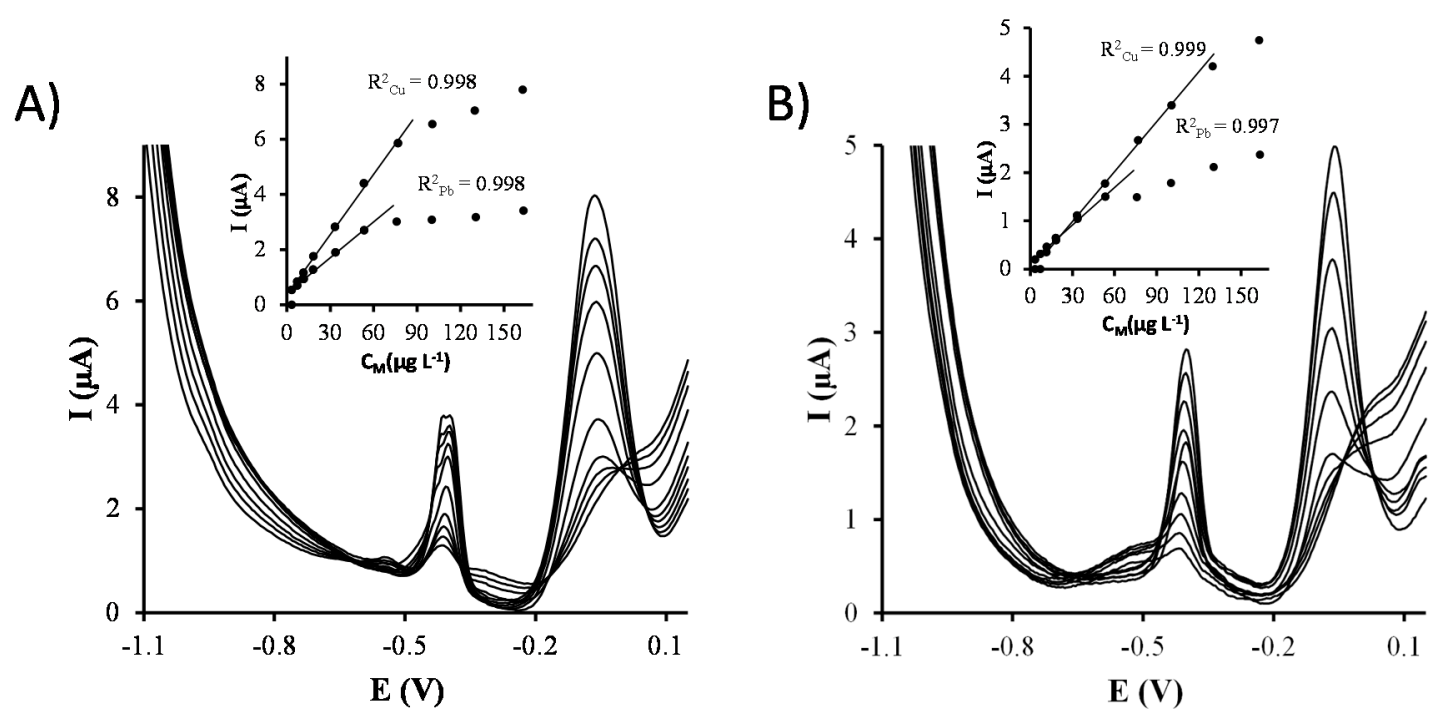

Figure 5. Stripping voltammetric measurements and calibration curves (insets) obtained for the simultaneous calibration of $\mathrm{Pb}$ (II) and $\mathrm{Cu}$ (II) in acetate buffer $\mathrm{pH} 4.5$ using an Ag-nanoseeds-SPCNFE (A) and an Ag-nanoprisms-SPCNFE (B) at an $E_{d}$ of $-1.1 \mathrm{~V}$ and $t_{d}$ of $120 \mathrm{~s}$.

\subsection{Application to the Analysis of a Groundwater Reference Material}

In view of the above discussed results, Ag-nanoseeds-SPCNFE was considered for the determination of $\mathrm{Cu}(\mathrm{II})$ and $\mathrm{Pb}(\mathrm{II})$ in natural samples. Thus, the applicability of this sensor was tested by simultaneously determining $\mathrm{Pb}$ (II) and $\mathrm{Cu}$ (II) in a groundwater certified reference material $\left(\mathrm{BCR}^{\circledR}\right.$-610). Figure 6 shows representative voltammograms for the simultaneous analysis of $\mathrm{Cu}(\mathrm{II})$ and $\mathrm{Pb}(\mathrm{II})$ in the groundwater reference material. $\mathrm{Pb}(\mathrm{II})$ and $\mathrm{Cu}(\mathrm{II})$ concentrations were determined using the standard addition method, and, as it can be observed, well defined peaks were obtained for both target ions like in the calibration samples.

Calibration curves for both $\mathrm{Pb}(\mathrm{II})$ and $\mathrm{Cu}$ (II) are shown in the inset of Figure 6. Good correlations were obtained in both cases. Three replicates of the simultaneous voltammetric determination of $\mathrm{Cu}(\mathrm{II})$ and $\mathrm{Pb}(\mathrm{II})$ in the groundwater certified material using Ag-nanoseeds-SPCNFE were carried out. The obtained concentration data is reported in Table 2. As it can be observed, good concordance between the replicates, inferred by the relative standard deviation (RSD), and with the certified metal ion concentration values were achieved. It should be mentioned that this groundwater material also contains other metal ions including cadmium, arsenic, aluminium and nickel, which do not seem to interfere in the voltammetric determination of $\mathrm{Cu}(\mathrm{II})$ and $\mathrm{Pb}(\mathrm{II})$ using Ag-nanoseeds-SPCNFE. 


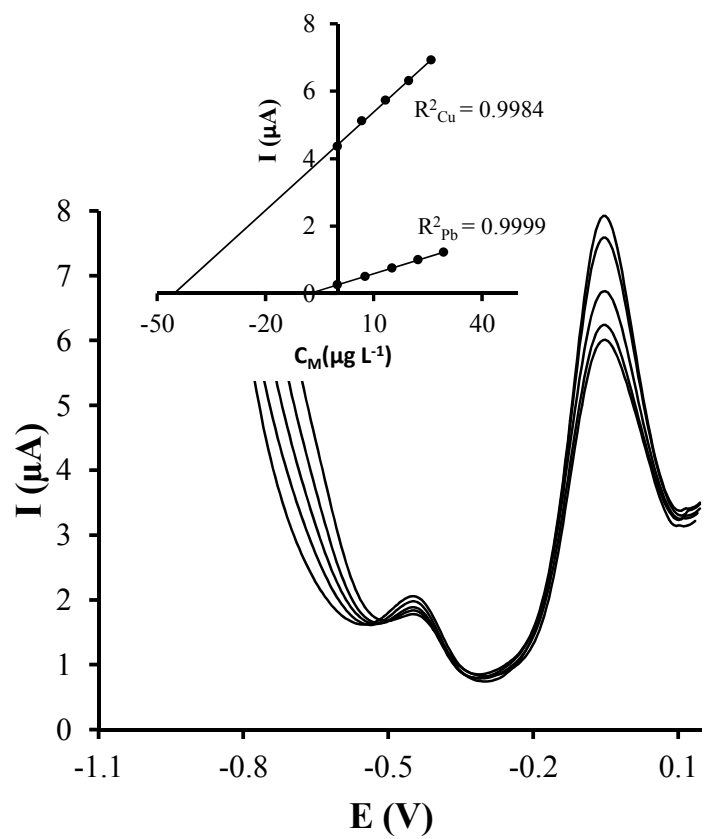

Figure 6. Stripping voltammetric measurements in groundwater samples on Ag-nanoseeds-SPCNFE at $\mathrm{pH} 4.5$ using an $\mathrm{E}_{\mathrm{d}}$ of $-1.1 \mathrm{~V}$ during a $\mathrm{t}_{\mathrm{d}}$ of $120 \mathrm{~s}$. Inset: $\mathrm{Pb}(\mathrm{II})$ and $\mathrm{Cu}(\mathrm{II})$ standard calibration plots.

Table 2. Total concentrations of $\mathrm{Pb}(\mathrm{II})$ and $\mathrm{Cu}(\mathrm{II})$ determined in certified groundwater $\left(\mathrm{BCR}^{\circledR}-610\right)$ by stripping voltammetry on Ag-nanoseeds-SPCNFE by the standard addition calibration method applying an $\mathrm{E}_{\mathrm{d}}$ of $-1.1 \mathrm{~V}$ and $\mathrm{t}_{\mathrm{d}}$ of $120 \mathrm{~s}$ at $\mathrm{pH} 4.5$.

\begin{tabular}{ccccccc}
\hline & \multicolumn{4}{c}{ Lead(II) } & \multicolumn{3}{c}{ Copper(II) } \\
\cline { 2 - 7 } & $\mathrm{c}\left(\mu \mathrm{g} \cdot \mathrm{L}^{-\mathbf{1}}\right)$ & RSD (\%) & Relative Error (\%) & $\mathrm{c}\left(\mu \mathrm{g} \cdot \mathbf{L}^{-\mathbf{1}}\right)$ & RSD (\%) & Relative Error (\%) \\
\hline Ag-nanoseeds-SPCNFE & 7.83 & 2.94 & 0.64 & 45.6 & 1.2 & 0.2 \\
Certified metal value & 7.78 & 1.67 & - & 45.7 & 3.3 & - \\
\hline
\end{tabular}

The achieved results confirm the applicability of the developed Ag-nanoseeds-SPCNFE for the simultaneous determination of $\mathrm{Cu}(\mathrm{II})$ and $\mathrm{Pb}(\mathrm{II})$ in natural samples at $\mu \mathrm{g} \cdot \mathrm{L}^{-1}$ levels. Therefore, Ag-nanoseeds-SPCNFE could be an interesting and valuable alternative to more conventional electrodes for the determination of metal ions, particularly in the case of $\mathrm{Cu}$ (II) where antimony and bismuth electrodes present some problems.

\section{Conclusions}

In this work, two different types of silver nanoparticles, Ag-nanoseeds and Ag-nanoprisms, were microscopically characterized and considered for the modification of carbon-based screen-printed electrodes and their application to the determination of $\mathrm{Cu}$ (II) and $\mathrm{Pb}$ (II). It should be pointed out that, in contrast to more sophisticated modification strategies, the incorporation of the silver nanoparticles to the electrode surface is based on a fast and easy procedure where silver nanoparticles solution is directly drop-casted.

The resulting sensors were microscopically and analytically characterized and compared to each other. Three different carbon substrates were tested and SPCNFE was selected because it provided better repeatability and reproducibility. Concerning the type of silver nanoparticle, both Ag-nanoseeds-SPCNFE and Ag-nanoprisms-SPCNFE provided similar repeatability, reproducibility, linear range and LODs. However, Ag-nanoseeds-SPCNFE showed higher sensitivities and their synthesis is easier. 
Furthermore, Ag-nanoseeds-SPCNFE was successfully applied to the simultaneous determination of $\mathrm{Cu}(\mathrm{II})$ and $\mathrm{Pb}$ (II) in a groundwater certified reference material, providing good reproducibility and trueness inferred by the $\mathrm{RSD}(2.94 \%$ for $\mathrm{Pb}$ (II) and $1.2 \%$ for $\mathrm{Cu}(\mathrm{II}))$ and the relative error $(0.64 \%$ for $\mathrm{Pb}(\mathrm{II})$ and $0.2 \%$ for $\mathrm{Cu}(\mathrm{II}))$, respectively. Therefore, these good results confirm the applicability of Ag-nanoseeds-SPCNFE for the simultaneous determination of $\mathrm{Cu}$ (II) and $\mathrm{Pb}$ (II) in natural samples.

Acknowledgments: This work is supported by the University of Barcelona, by the Spanish Ministry of Economy and Competitiveness (MINECO, Spain) for Project ENE2014-54299-C2-1-R and by the Generalitat of Catalonia (Project 2014SGR269). Clara Pérez-Ràfols acknowledges the Spanish Ministry of Economy and Competitiveness for a Ph.D. grant.

Author Contributions: Julio Bastos-Arrieta, Clara Pérez-Ràfols and Núria Serrano conceived and executed the experimental work. Julio Bastos-Arrieta carried out the synthesis and microscopic characterization of silver nanoparticles and Clara Pérez-Ràfols and Núria Serrano carried out the modification of screen-printed electrodes with nanoparticles, the voltammetric measurements and the data treatment. José Manuel Díaz-Cruz discussed the first results with them and suggested additional experiments with bare silver electrodes. The first draft of the manuscript was prepared by Julio Bastos-Arrieta, Clara Pérez-Ràfols and Núria Serrano, and it was revised and substantially improved by José Manuel Díaz-Cruz, Cristina Ariño, Joan de Pablo and Miquel Esteban.

Conflicts of Interest: The authors declare no conflict of interest.

\section{References}

1. Wang, J. Stripping Analysis: Principles, Instrumentation and Applications; VCH: New York, NY, USA, 1985.

2. Barek, J.; Fogg, A.G.; Muck, A.; Zima, J. Polarography and voltammetry at mercury electrodes. Crit. Rev. Anal. Chem. 2001, 31, 291-309. [CrossRef]

3. Serrano, N.; Alberich, A.; Díaz-Cruz, J.M.; Ariño, C.; Esteban, M. Coating methods, modifiers and applications of bismuth screen-printed electrodes. Trends Anal. Chem. 2013, 46, 15-29. [CrossRef]

4. Wang, J.; Lu, J.; Anik, Ü.; Hocevar, S.B.; Ogorevc, B. Insights into the anodic stripping voltammetric behavior of bismuth film electrodes. Anal. Chim. Acta 2001, 434, 29-34. [CrossRef]

5. Yang, D.; Wang, L.; Chen, Z.; Megharaj, M.; Naidu, R. Investigation of copper(II) interference on the anodic stripping voltammetry of lead(II) and cadmium(II) at bismuth film electrode. Electroanalysis 2013, 25, 2637-2644. [CrossRef]

6. Serrano, N.; Díaz-Cruz, J.M.; Ariño, C.; Esteban, M. Antimony-based electrodes for analytical determinations. Trends Anal. Chem. 2016, 77, 203-213. [CrossRef]

7. Sosa, V.; Barceló, C.; Serrano, N.; Ariño, C.; Díaz-Cruz, J.M.; Esteban, M. Antimony film screen-printed carbon electrode for stripping analysis of $\mathrm{Cd}(\mathrm{II}), \mathrm{Pb}(\mathrm{II})$, and $\mathrm{Cu}(\mathrm{II})$ in natural samples. Anal. Chim. Acta 2015, 855, 34-40. [CrossRef] [PubMed]

8. Uslu, B.; Ozkan, S.A. Solid electrodes in electroanalytical chemistry: Present applications and prospects for high throughput screening of drug compounds. Comb. Chem. High Throughput Screen. 2007, 10, 495-513. [CrossRef] [PubMed]

9. Herzog, G.; Arrigan, D.W. Determination of trace metals by underpotential deposition-stripping voltammetry at solid electrodes. Trends Anal. Chem. 2005, 24, 208-217. [CrossRef]

10. Aragay, G.; Merkoçi, A. Nanomaterials application in electrochemical detection of heavy metals. Electrochim. Acta 2012, 84, 49-61. [CrossRef]

11. Tukur, S.A.; Azahyusof, N. Metallic nanoparticles for modification of electrodes for heavy metals detection. Asian J. Chem. 2015, 27, 1967-1969. [CrossRef]

12. Wanekaya, A.K. Applications of nanoscale carbon-based materials in heavy metal sensing and detection. Analyst 2011, 136, 4383-4391. [CrossRef] [PubMed]

13. Arcos-Martınez, M.J.; Dominguez-Renedo, O. A novel method for the anodic stripping voltammetry determination of $\mathrm{Sb}$ (III) using silver nanoparticle-modified screen-printed electrodes. Electrochem. Commun. 2007, 9, 820-826. [CrossRef]

14. Xing, S.; Xu, H.; Chen, J.; Shi, G.; Jin, L. Nafion stabilized silver nanoparticles modified electrode and its application to Cr (VI) detection. J. Electroanal. Chem. 2011, 652, 60-65. [CrossRef]

15. Prakash, S.; Shahi, V.K. Improved sensitive detection of $\mathrm{Pb}^{2+}$ and $\mathrm{Cd}^{2+}$ in water samples at electrodeposited silver nanonuts on a glassy carbon electrode. Anal. Methods 2011, 3, 2134-2139. [CrossRef] 
16. Barton, J.; González-García, M.B.; Hernández-Santos, D.; Fanjul-Bolado, P.; Ribotti, A.; McCaul, M.; Diamond, D.; Magni, P. Screen-printed electrodes for environmental monitoring of heavy metal ions: A review. Microchim. Acta 2016, 183, 503-517. [CrossRef]

17. Honeychurch, K.C. Screen-printed electrochemical sensors and biosensors for monitoring metal pollutants. Insci. J. 2012, 2, 1-51. [CrossRef]

18. Vogel, A.I. Quantitative Chemical Analysis, 5th ed.; Pearson Education Limited: Harlow, UK, 1989.

19. Aherne, D.; Ledwith, D.M.; Gara, M.; Kelly, J.M. Optical properties and growth aspects of silver nanoprisms produced by a highly reproducible and rapid synthesis at room temperature. Adv. Funct. Mater. 2008, 18, 2005-2016. [CrossRef]

20. Aherne, D.; Gara, M.; Kelly, J.M.; Gun'Ko, Y.K. From Ag Nanoprisms to Triangular AuAg Nanoboxes. Adv. Funct. Mater. 2010, 20, 1329-1338. [CrossRef]

21. Espinoza-Castañeda, M.; de la Escosura-Muñiz, A.; González-Ortiz, G.; Martín-Orúe, S.M.; Pérez, J.F.; Merkoçi, A. Casein modified gold nanoparticles for future theranostic applications. Biosens. Bioelectron. 2013, 40, 271-276. [CrossRef] [PubMed]

22. Muñoz, J.; Bastos-Arrieta, J.; Muñoz, M.; Muraviev, D.N.; Céspedes, F.; Baeza, M. CdS quantum dots as a scattering nanomaterial of carbon nanotubes in polymeric nanocomposite sensors for microelectrode array behavior. J. Mater. Sci. 2015, 51, 1610-1619. [CrossRef]

23. Nikoobakht, B.; El-Sayed, M.A. Preparation and growth mechanism of gold nanorods (NRs) using seed-mediated growth method. Chem. Mater. 2003, 15, 1957-1962. [CrossRef]

24. Pérez-Ràfols, C.; Serrano, N.; Díaz-Cruz, J.M.; Ariño, C.; Esteban, M. New approaches to antimony film screen-printed electrodes using carbon-based nanomaterials substrates. Anal. Chim. Acta 2016, 916, 17-23. [CrossRef] [PubMed]

25. Cong, H.; Yu, B.; Tang, J.; Li, Z.; Liu, X. Current status and future developments in preparation and application of colloidal crystals. Chem. Soc. Rev. 2013, 42, 7774-7800. [CrossRef] [PubMed]

26. Bonfil, Y.; Kirowa-Eisner, E. Determination of nanomolar concentrations of lead and cadmium by anodic-stripping voltammetry at the silver electrode. Anal. Chim. Acta 2002, 457, 285-296. [CrossRef]

27. Plieth, W.J. Electrochemical properties of small clusters of metal atoms and their role in the surface enhanced Raman scattering. J. Phys. Chem. 1982, 86, 3166-3170. [CrossRef]

28. Serrano, N.; González-Calabuig, A.; del Valle, M. Crown ether-modified electrodes for the simultaneous stripping voltammetric determination of $\mathrm{Cd}(\mathrm{II}), \mathrm{Pb}(\mathrm{II})$ and $\mathrm{Cu}(\mathrm{II})$. Talanta 2015, 138, 130-137. [CrossRef] [PubMed]

29. Liu, G.; Quynh, T.N.; Chow, E.; Böcking, T.; Hibbert, D.B.; Gooding, J.J. Study of factors affecting the performance of voltammetric copper sensors based on Gly-Gly-His modified glassy carbon and gold electrodes. Electroanalysis 2006, 18, 1141-1151. [CrossRef]

30. Bobrowski, A.; Putek, M.; Zarebski, J. Antimony film electrode prepared in situ in hydrogen potassium tartrate in anodic stripping voltammetric trace detection of $\mathrm{Cd}(\mathrm{II}), \mathrm{Pb}(\mathrm{II}), \mathrm{Zn}(\mathrm{II}), \mathrm{Tl}(\mathrm{I}), \mathrm{In}(\mathrm{III})$ and $\mathrm{Cu}(\mathrm{II})$. Electroanalysis 2012, 24, 1071-1078. [CrossRef]

31. Slavec, M.; Hocevar, S.B.; Baldrianova, L.; Tesarova, E.; Svancara, I.; Ogorevc, B.; Vytras, K. Antimony film microelectrode for anodic stripping measurement of cadmium(II), lead(II) and copper(II). Electroanalysis 2010, 22, 1617-1622. [CrossRef]

32. Sang, S.; Li, D.; Zhang, H.; Sun, Y.; Jian, A.; Zhang, Q.; Zhang, W. Facile synthesis of AgNPs on reduced graphene oxide for highly sensitive simultaneous detection of heavy metal ions. RSC Adv. 2017, 7, 21618-21624. [CrossRef]

33. Pérez-Ràfols, C.; Serrano, N.; Díaz-Cruz, J.M.; Ariño, C.; Esteban, M. Glutathione modified screen-printed carbon nanofiber electrode for the voltammetric determination of metal ions in natural samples. Talanta 2016, 155, 8-13. [CrossRef] [PubMed]

34. Pérez-Ràfols, C.; Serrano, N.; Díaz-Cruz, J.M.; Ariño, C.; Esteban, M. Penicillamine-modified sensor for the voltammetric determination of $\mathrm{Cd}(\mathrm{II})$ and $\mathrm{Pb}(\mathrm{II})$ ions in natural samples. Talanta 2015, 144, 569-573. [CrossRef] [PubMed] 